drying up, and only a sufficient number to do the work being retained on duty, the others going to the reserve (Trans. Roy. Soc. Edin. vol. xxxvii. Part ii. No. 20). It may be also as well to remember that even supposing all the dust to be precipitated out of the air, nature may be able to manufacture fresh supplies (Trans. Roy. Soc. Edin. vol. xxxix. Part i. No. 3). If there are any gaseous impurities in the air, such as ammonia, nitric acid, nitrous acid, peroxide of hydrogen, sulphurous acid, sulphuretted hydrogen, hydrochloric acid or chlorine, the sunshine will convert them into nuclei, which do not require a high degree of supersaturation to make them active centres of condensation.

There is another point in connection with condensation by means of ions which may be referred to here. It does not seem probable that ions could ever cause the formation of a cloud though they might give rise to rain. If the air becomes so supersaturated as to make them active centres of condensation, it will then be in an unstable condition. It will, in fact, be in an explosive state--explosive centripetally and not centrifugally as usual. Whenever any ion, in air in that condition, owing to any advantage of its constitution, or difference of temperature, pressure, or saturation in the air surrounding it becomes active before the others, it will grow extremely rapidly, and at once begin to fall ; and as it will fall through highly supersaturated air, it will relieve the tension all along its path, and so grow rapidly, and soon become a rain-drop and fall to the earth. In Mr. Wilson's experiments cloudy condensation takes place with ions as nuclei, but in his apparatus the expansion is nearly instantaneous, and no particular ion has time to take advantage over the others, and many are thus formed at the same instant. There is still another point which requires consideration. What would the effect be in a rising column of air if it could not call on the reserve heat, latent in its vapour, till it had risen to a higher elevation than is necessary when dust is present.

So far as our knowledge goes, it can hardly be said there is such a thing as dust-free air in our atmosphere, and the cases in which low numbers have been observed are so extremely rare that they can hardly have any bearing on a phenomena of such widespread existence as atmospheric electricity, even though we suppose those few particles to be afterwards got rid of. We cannot suppose the positive ions will always remain in the atmosphere, because if the conditions are ever such as to cause the fall of the negative ions, the positive ones will also afterwards fall with only a slightly greater increase in supersaturation.

From what has been stated above, I think we must defer expressing an opinion on the value of this theory of the source of atmospheric electricity, and wait till some stronger evidence is produced that the air in our atmosphere is ever absolutely dustfree, so as to permit of the supersaturation becoming great enough to cause a separation of the negative and positive ions.

Ardenlea, Falkirk, March i 7. JOHN AitKEN.

\section{Escape of Gases from Planetary Atmospheres.}

IN the "Astronomical Column" of last week's NATURE, on p. 50I, you give an abstract of a paper by Mr. S. R. Cook, of the University of Nebraska, and quote the passage in which he points out that the present writer, when investigating the escape of gases from atmospheres, does not base his argument upon $\approx$ the determination by the kinetic theory of the relative number of molecules which would have a velocity sufficient to enable them to escape from the earth or planet."

This is so: and the reason is that no such determination existed until that arrived at in the paper criticised by Mr. Cook, where data drawn from outside the kinetic theory are employed to supplement what the kinetic theory teaches. These auxiliary data are (I) that the moon has not retained an atmosphere; and (2) that the earth and Venus do retain the vapour of water in their atmospheres.

Mr. Cook supposes that Maxwell's law for the distribution of the speeds of the molecules when a gas exists under normal conditions may legitimately be employed to obtain the rate of the escape from an atmosphere. But in this he overlooks ( $\mathrm{I}$ ) the fact that the molecules that escape are emitted exclusively from that outermost layer of the atmosphere, throughout which the molecules are within striking distance of the void space beyond; and (2) the important circumstance that the molecules exist within this altogether special layer under conditions entirely remote from those which are assumed by Maxwell in the proof $^{1}$ of his law ; so that Maxwell's law fails us just where we want its help, viz. in that part of the atmosphere from which the entire of the escape of molecules takes place.

This upper stratum of the atmosphere, which is probably some miles in depth, is limited on its inner side by a deeper-seated stratum of air, and on the outer side by a stratum of virtually empty space, that is, by a space tenanted only by molecules which seldom or never meet with encounters while within that space, and are therefore to be regarded as temporarily or permanently beyond the atmosphere. As to the stratum which is above spoken of as the outermost of the atmosphere, molecular encounters take place in it ; and whenever an unusual speed is generated in any of the molecules which occupy it (as happens frequently to every molecule of a gas) these molecules have an opportunity of placing themselves beyond the reach of those subsequent encounters which, in gas under normal conditions, are what tone down the frequently recurring irregularities, and bring about an approximate conformity with Maxwell's law within a sufficient volume of gas of uniform density, and surrounded by gas of the same density.

Nevertheless, the numerical results obtained by Mr. Cook, though arrived at by a faulty process, are not useless. They have a certain value, inasmuch as it can be proved that the actual escape of gases from an atmosphere is more rapid than it would be if Maxwell's law governed that rate. Accordingly, Mr. Cook's numbers furnish a computed rate which we know that the actual rate must exceed, and may largely exceed. This in itself is valuable information; and would be important information, if we had no better way of investigating the problem.

Like Mr. Cook, the present writer, when he first entered on the investigation of the escape of gases from atmospheres in 1867 or 1868 , hoped that Maxwell's law for the distribution of the speeds of the molecules under normal conditions would render aid; and it was only when he found that to conduct the inquiry in this way could not furnish correct results, that he cast about for some other way of approaching the problem, and finally adopted that which is developed in his memoir."

8 Upper Hornsey Rise, N., March 25. G. JOHNSTONE STONEY.

\section{State of Practical Instruction in Physics.}

WiTH the view of obtaining comparative statistics of the organisation of practical instruction in physics, I have recently sent a list of questions, with table of different manipulations, to the directors of all the physical laboratories with the addresses of which I am acquainted.

Through the medium of your esteemed journal, may I ask the directors of the laboratories, who, by any reason whatever, have not received this list, kindly to inform me, so that I may at once forward the same. I should like to make the same appeal to the directors of the mechanical, electrical engineering, electrochemical, physico-chemical, \&c., laboratories where part of the practical work is of a purely physical character.

University of Odessa, Russia, March 17 .

\section{Indian Corn.}

I HAVE just found in Nakamura's "Kimmō Dzui," first edition, 1666, Book xvi. fol. $7 b$, a Japanese wood-cut of Indian corn, with its Japanese and Chinese names as I gave in my previous letter (p. 392, ante). This figure proves that, though Kaempfer does not mention the plant in his "History of Japan," 1727, yet, through his seeing to it, he must have recognised as a fact the introduction of maize to Japan before the time of his sojourn in it ; for most illustrations of the biological objects in his noted " History" (vol. i. tab. ix.-xiv.) are actually found to have been reproduced from the above-mentioned, once very popular, Japanese cyclopredia (Books xii.-xv.).

Kumagusu Minakata.

I Crescent Place, South Kensington, S. W., March 9.

The Bacteriology of the Soil.

I SHOULD be much obliged if, through the columns of NATURE, you would give me the names of the best books in English or German which deal with soil (agricultural) bacteria.

Thos. T. WATSON.

Rosely Cottage, Collier Street, Carnoustie, March 26.

${ }^{1}$ See Phil. Mag. for January 1860, p. 22 ; or vol, i. of his "Collected Papers," p. $3^{80}$

- See Scientific Transactions of the Royal Dublin Society, vol. vi. Part ${ }_{13}$; or Astropinysical Journal for January 1898 . 